\title{
TOWARDS SUSTAINABLE BUILDINGS USING BUILDING INFORMATION MODELLING AS A TOOL FOR INDOOR ENVIRONMENTAL QUALITY AND ENERGY EFFICIENCY
}

\author{
AHMED ALI SHABAN ABDELAZIM, MOHAMED ABDELAAL \& WALID MOHAMED \\ Department of Architecture, Faculty of Engineering, Alexandria University, Egypt
}

\begin{abstract}
Nowadays, many people suffer within the existing buildings from problems related to human comfort and energy consumption. The poor quality of the internal environment of buildings for instance uneven temperatures, inadequate ventilation, humidity, poor lighting, acoustics, and noise pollution leads people to use methods that harm the environment. The objective has always been in green thought existing from the continue sustainably. By reviewing the literature illustrating the contributions of BIM to sustainability and its applications in achieving indoor environmental quality within public buildings through conserving energy, natural resources and respecting the needs of its users. So, the field of research is How can BIM is applied to accomplish sustainable Public and housing buildings. BIM technology has created significant benefactions firstly in the design phase, then construction stage, finally in the process of operation, and other perspectives of sustainable buildings. This paper aims to understand BIM technology, its relationship to the sustainability of buildings. This is done by conducting a questionnaire on specialized organizations and companies to learn about the dimensions of BIM and the extent of its use. In addition to discussing the positive and negatives of BIM in sustainable design processes and coming up with a working method that can be applied. The consequences of the questionnaire and analysing literature show that the contribution, restrictions, and barriers of applying BIM for developing sustainable buildings have not been precisely analysed and explained yet. The overlap between BIM and building sustainability needs to be demonstrated practically. The application of BIM in a large number of examples is required to show positive results in raising the quality of the indoor environment and energy efficiency. These solutions which BIM introduces help designers increase the performance of buildings, thus maintaining the life cycle of cities and achieving a suitable quality of life for the inhabitants of the 21 st century.

Keywords: BIM, energy efficiency, green building, indoor environmental quality, sustainability, sustainable buildings.
\end{abstract}

\section{INTRODUCTION}

Currently, sustainability is a top priority in the agenda of the international community pursued by decision-makers in all aspects of life. Architecture and cities are a reflection of society. There is a strong race among construction workers to achieve more sustainable buildings than other traditional buildings that people are accustomed to. It is necessary to clarify the meaning of sustainable building here. In the previous literature, there are many discussions and studies of the thought of sustainable buildings. These modern explanations can be summarized that sustainable building can be described as a healthy facility created and built in a cradle-to-grave resource-effective pattern, using ecological principles, social equity, life-cycle quality value, etc. promotes a sense of sustainable community [1].

To fully achieve sustainability in buildings, it is necessary here to identify the factors that affect sustainability. After extensive research, sustainability can be reduced to four main headings according to research topics such as water, indoor environmental quality, energy, materials, and waste minimization [2]. Then comes the powerful role of BIM, which is a great tool for achieving sustainability goals. It is noted that the link between 
BIM and sustainability has been mentioned in the literature significantly lately. The National BIM Standard-United States describes BIM as "the action of producing an electronic model of buildings for the goal of visualization, architecture analysis, interpretation analysis, code standards checking, expense engineering, as-built output, budgeting, and a lot of other purposes" [3].

BIM is understood as a potentially promising powerful driver guiding the construction and plaining sectors towards sustainability. BIM aims at a high-efficiency construction project. As one of the main applications of BIM, sustainable building construction is driven by energy-efficient [4]. The traditional architectural model faces challenges such as lack of information exchange and low work efficiency at various stages. BIM is a modern technological method that is highly recommended by the construction industry and government authorities [5]. The birth of BIM is based on the combination of construction techniques and information technologies, leading to a revolution in the modern construction industry [6].

The most progressing BIM can reach up to eight dimensions which proposes which it is a $3 \mathrm{D}$ visualized conception. It benefits to program and presents the projected growth along over with forecasts $(4 \mathrm{D}=$ time and schedule). It gives in real-time all cost-data, so it draws an actual budget $(5 \mathrm{D}=$ cost $)$. The sixth dimension facilities management $(6 \mathrm{D}=$ operation $)$, then the model also provides environmental impact analysis $(7 \mathrm{D}=$ Sustainability $)$. The eighth Dimension is about security on site: emergency plans. It prevents security issues (8D $=$ safety) [7].

The research focuses on the seventh purpose of BIM models and the overlay connecting BIM and sustainable design. Architects can quantify the environmental influences of systems and materials to support the determinations needed to produce sustainable buildings, using essential information about sustainable materials that are saved in the database and compatibility between the design process and analysis tools. Such data is useful for building life cycle assessments and important to enhance the internal environment in the design process, which are indoor air quality, Moisture comfort, thermal comfort, lighting comfort, and acoustic comfort.

Architects and engineers become more capable to digitally model the different components of a building (shape, structure, heating/cooling, cost, materials, etc.) in realtime and quickly understand how specific changes in design or construction models will impact other variables like structure, loads, energy efficiency and the fiscal bottom line. BIM has particularly helped empower sustainable design which providing architects with a particular path to high-tech means to carefully integrate parameters like heat gain, ventilation, solar, and energy efficiency. Hence the term BIM in Green Building, or "Green BIM," is a process that can help architecture, engineering, and construction companies increase sustainability in the construction industry. It can allow designers to incorporate and analyse environmental issues in their design over the life series of a building [8].

The benefit of a BIM process is that many types of analysis and simulation can take place as part of the design process, enabling engineers quickly to cycle through experiments and get instant feedback on project achievement. Another advantage of a BIM process is that all reports can be saved in a cloud database. Thus, all information is parametric and that way interconnected, thus making it available for all project partners. Accordingly, a BIM model could be managed holistically during the design-to-build-to-own process since any changes to the BIM model are instantly revealed, thereby promoting up the project process.

This paper is structured in six sections: Section 1 a quick review of sustainability and its relationship to BIM, Section 2 Clarification of the research method and its steps, whereas 
Section 3 Presentation of the questionnaire, how to implement it, and the results reached. Section 4 Discuss the results and analyse them. Review the benefits and obstacles that BIM faces in achieving sustainable buildings and, finally, Section 5 summarizes the findings of this work (Fig. 1).

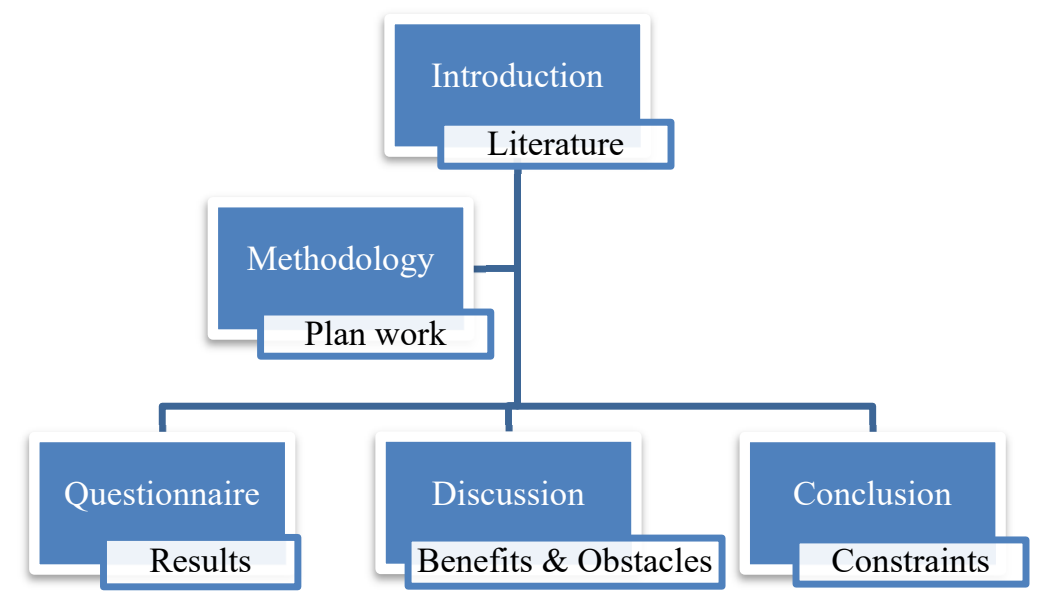

Figure 1: Research structure.

\section{METHODOLOGY}

The research aims to clarify the contributions of BIM to sustainable building processes, especially on the levels of indoor environmental quality and indoor energy efficiency. With the increasing use of this technology worldwide, the researcher first wants to stand on solid ground and have a clear vision of the extent of using BIM at the local level. The research begins with the conduct of a local questionnaire in Alexandria, Egypt. The extent to which BIM is used in the institutions and offices of architecture, construction, and engineering is determined by asking them a set of questions.

By analysing the results, the positive aspects are quickly highlighted. But more emphasis is placed on the negatives related to the use of BIM to achieve sustainability in the buildings. A discussion of the means and tools that are being used to achieve sustainability is held. In addition to analysing previous successful models in the literature and case studies that achieved tangible and measured successes. Finally, the conclusion comes which clarifying the results of the research. With giving a set of recommendations that help activate the role of BIM in sustainable design.

\section{QUESTIONNAIRE AND DATA GATHERING}

Through online interviews and site investigation, some closely related companies have selected and are ready to provide answers to the questionnaire. It's issued questionnaires to more than 30 relevant engineers. The questionnaire includes 15 questions with the subsequent viewpoints:

1. Individual Information, qualifications of the taskmaster, BIM training of users, length of serving, and which BIM software is used.

2. Application of BIM in different dimensions in the ACE sector from $2 \mathrm{D}$ shapes, 3D visualization, 4D schedule, 5D cost, 6D operation, 7D sustainability, and 8D safety. 
3. The possible contribution of BIM to sustainable buildings. In addition, asking about the specific contributions of BIM in building water preservation, indoor environmental quality, energy efficiency, materials, and waste minimization.

4. Factors that impede BIM application to sustainable buildings are classified into technology, budgetary constraints, social environment, and resource management.

Before distributing the questionnaires, the researcher seeks to determine interviews closely linked to the building and construction shareholders and BIM. Various organizations are chosen closely related and ready to give feedback to the questionnaire through online discussions and site inventory. The honesty and validity of the questionnaire are analysed through its review of three questionnaires and opinion poll specialists. The results of the analysis show that the questionnaire results are valid and reliable after deleting some questions. Based on the research conclusions, policies have been suggested to promote effectively sustainable buildings through BIM.

However, before starting the discussion process, there is a need to know the areas of using BIM technology on the ground in the design process. And to what extent are they used by professionals in the processes of (ACE) in the eight dimensions mentioned before? This is clearly shown in Fig. 2.

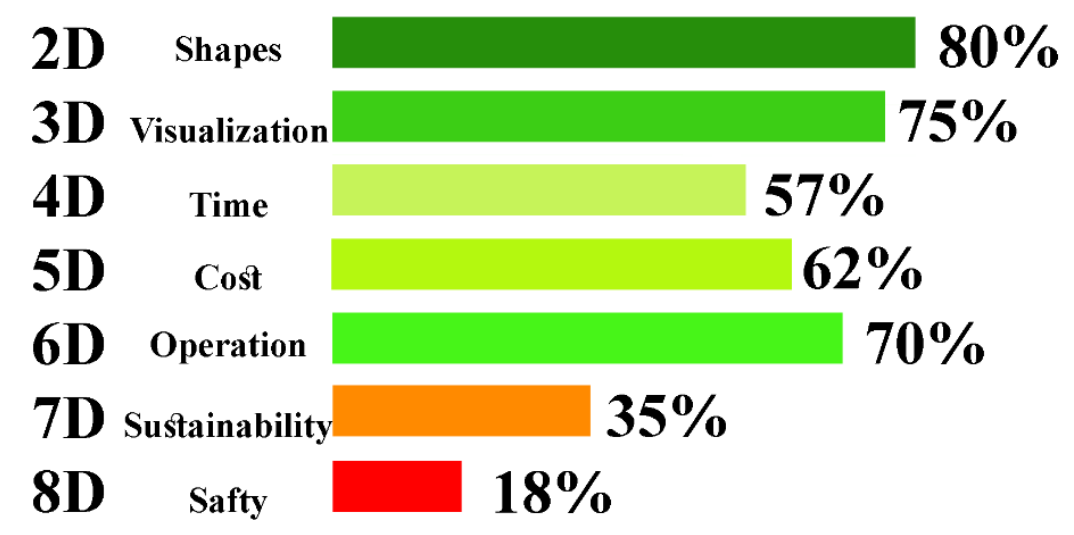

Figure 2: Dimensional frequency diagram for which BIM is used extensively in the design process.

The intensity of the use of BIM in the design process can be divided into three parts. In the foreground comes the use of BIM in two-dimensional drawing operations, as well as making 3D models and external and internal perspectives of buildings. Then it is followed by strongly above-average application of BIM in management, operation, assays, quantities, specifications, determining budgets, costs, schedules, and timelines for the start and end of projects. Finally, at a weak level, but in recent times it is considered promising, which is the use in the field of sustainability, especially in the quality of the internal environment and energy efficiency, as well as safety and security operations inside the workplace. Therefore, in the next part, the contribution and obstacles of BIM in green buildings are analysed by reviewing the questionnaire and the results deduced from it. 


\section{DISCUSSION, BENEFITS, AND OBSTACLES}

Although researchers have discovered many benefits and hurdles of BIM, the participation of BIM to sustainable buildings is not clear. Through the questionnaire conducted by the research, a set of these benefits and obstacles that designers currently face were identified. Moreover, a search for solutions and methodologies in the literature can be applied.

\subsection{BIM's contribution to increasing sustainable buildings}

Participants think that within BIM software, designers can merge design numerous conveniently. BIM helps users to be more efficient in making design drawings and blueprints, promotes their interaction efficiency with the owners. BIM Technology can straight give targeted information in succession with multiple construction circumstances and put ahead reasonable recommendations for sustainable buildings. Compared with conventional buildings, sustainable building design is a complex work that needs to consider many factors, such as energy-saving analysis, daylighting analysis, sunshine analysis, etc... According to the summary of the questionnaire, it is obvious that BIM can act a significant role in energy preservation, material maintenance, and conserving, improving indoor and outside environments [9].

BIM technicality can additionally support increasing the availability area of outer windows, facilitate accurate simulation of sunlight, and promote natural lighting inside and underground. BIM technology can apprehend the demands of group analysis, centralized presentation, a quick calculation of data, and reports needed for sustainable buildings. All of these would achieve better green energy-saving and produce an extra relaxed living environment for people. In addition, the sustainable building evaluation method can be hugely optimized by BIM's characteristics as simulation and visualization. With BIM, the sustainable building valuation issues can too be recorded easily and traced.

\subsection{BIM obstacles in design sustainable building}

BIM has good application potential in sustainable buildings. However, many barriers remaining are still, including:

The paradox of BIM software measures and criteria are the most significant obstruction from the technology viewpoint. Not only the shortage of technical criteria but also the delivery criteria of BIM document Production without elaboration. All of these led to numerous disturbances for users in terms of management and control.

The shortage of interactivity among the multiple applications comes second. It is a really essential restriction in the technology aspect. Until now, there are more than a hundred types of BIM software, when software programmers ordinarily only think about the adaptability and flexibility among software in fields they used. Resulting in inadequate interactivity which hugely limits the communication and interchange of information amongst the software. In order to actualize sustainable mentality by using BIM, it should rely on collaboration among the software. At present, it takes a lot of time to build a new building model by importing the information contained in the BIM model into the software of each stage, which leads to the low practicability of the BIM technology [10]. For example, BIM and energy simulation takes place in three main steps: (1) BIM Generate tool, (2) BIM file, (3) Energy simulation tool. Problems often appear when going between these steps. Energy simulation software could be constituted of two major components. The first one is a Graphic User Interface and the second one is a simulation engine. GUIs such as Open Studio, BEopt, Design Builder, and EQuest promote the energy simulation method 
by implementing a graphical interface for designers. Nevertheless, the second component, which is the energy simulation engines as Energy Plus and Doe2 runs following these tools. BIM file schemas are the second link of the chain. IFC and gbXML extensions are two of the most common types of files, which could carry information on diverse aspects of buildings. In Table 1 shows how common energy simulation tools are aggregated under either energy simulation GUI or simulation engine. In Table 1 shows how common energy simulation tools are aggregated under either energy simulation GUI or simulation engine [11].

Table 1: Categories of energy simulation tools [11].

\begin{tabular}{|c|c|c|}
\hline Energy simulation GUI only & Energy simulation engine & $\begin{array}{l}\text { Independent energy simulation } \\
\text { engine with graphical interface }\end{array}$ \\
\hline $\begin{array}{l}\text { OpenStudio } \\
\text { DesignBuilder } \\
\text { Hevacomp } \\
\text { Simergy } \\
\text { BEopt }\end{array}$ & EnergyPlus & $\begin{array}{c}\text { Ecotect } \\
\text { TRNSYS } \\
\text { IDA ICE } \\
\text { ApacheSim (used in IES VE) } \\
\text { EDSL Tas }\end{array}$ \\
\hline $\begin{array}{l}\text { GBS } \\
\text { eQuest } \\
\text { RIUSKA }\end{array}$ & DOE2 & $\begin{array}{l}\text { Modelica language (can be used with } \\
\text { graphical interfaces such as Dymola) }\end{array}$ \\
\hline
\end{tabular}

Based on this explanation, it appears there is still a demand for extensive research on the abilities and skills of these BIM file standards and their interoperability characteristics with various BIM and energy simulation tools to recognize all the latent shortcomings.

The high cost of software, hardware, and maintenance grant and the doubts of BIM expense returns. This high cost of software is clearly visible in the initial cost when adding the BIM to the workflow of the company. This cost includes training BIM technicians, hardware upgrades, licenses for using BIM programs, establishing standard libraries, and the possibility of duplication and returning to programs for two-dimensional graphics for use. However, when balancing the high initial cost against the cost of current tools and labour, saving time and increased working hours when making adjustments and correcting errors that appear during implementation processes. The transition to using BIM technology will save more effort and budget [12]. In the issue of public and environmental obstructions, incomplete BIM standards, the lack of proper Politicking directing and support the major obstacle. Many respondents consider that the sharp deficiency of BIM specialists in companies is also a hindrance that cannot be ignored.

The shortage of knowledge and applicability of standards such as ISO 19650 is a significant difficulty, for example, lack of necessities, minimum preparation, not examining the method of model evolution and replacement, and delaying sustainability to the end steps in the operation process, which leads to it being a complementary and non-essential step in the design process.

The inconsistency of BIM software standards, Of course, is not necessarily correct. But this happens due to the lack of knowledge, experience, and understanding of global standards for BIM, for example, but not limited to ISO 19650. It is a universal standard for managing and handling information across the whole life cycle of a constructed asset using BIM. It includes all the identical policies, principles, and essential requirements Like as United Kingdom BIM Framework, and is almost followed by the contemporary UK 1192 regulations and restrictions. 
There are many other problems, but what is of interest to this research is summarized that the lack of smooth connection between BIM and sustainable building simulation tools such as Energy Plus, FLUENT, PKPM, and e-QUEST [11]. While BIM is mainly used in the building design phase, it fails to provide adequate support for subsequent phases such as operation and maintenance. However, they are considered key evaluation stages for sustainable buildings. Therefore, a clear and proven practical method must be found that achieves the desired goal of using BIM in sustainable design.

\subsection{Methodology for design sustainable buildings}

The application process of implementing BIM for indoor environmental performance analysis is in general terms highlighted by Fig. 3. The suggestion of process is based on the circumstances of a smart 3D augmented simulation construction form, provided by containing all features of the building information into an intelligent format. This method is used to improve the sustainable performance of a building before committing to the design process [13]. That is Meaning after evaluating an initial indoor environmental performance analysis and quality. It is reasonable to modify the building design for performance enhancements.

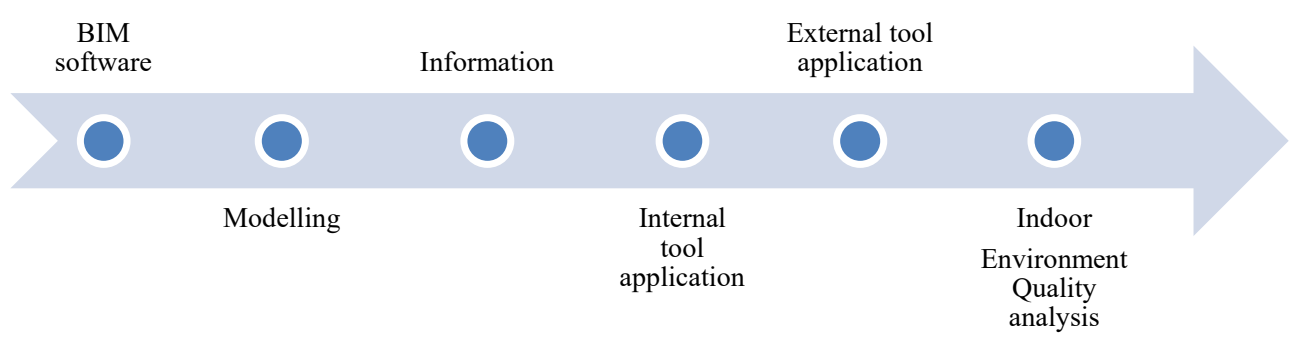

Figure 3: The BIM workflow for indoor environmental quality analysis.

Likewise, the indoor environment is related to buildings' energy consumption. Therefore, the research focuses on achieving the quality of the internal environment, which in turn will achieve energy saving and efficiency. Furthermore, the costs of a poor indoor environment are often more expensive than the expenses of regular energy used in the building due to the lower performance of the users, whether residents or workers. It is important to analyse all parameters of the internal environment in the design process, which are indoor air quality, Moisture comfort, thermal comfort, lighting comfort, and Comfortable acoustic range. With all these parameters, BIM can raise its efficiency and deal with to achieve the quality of the internal environment.

\section{CONCLUSION}

BIM is taking important steps to become the Ideal technology for users in the ACE industry. There is no doubt that BIM is facing many difficulties now to reach this position. However, the current and future research plans are considered promising and predict many positives in the coming periods.

This study discusses the contribution of BIM to sustainable buildings. Through the questionnaire, it is concluded that because the usage of BIM increases in its first dimensions, the seventh dimension of sustainability is nevertheless in its cradle. BIM can 
raise indoor environmental quality and achieve energy efficiency by improving indoor air quality, Moisture comfort, thermal comfort, lighting comfort, and acoustic comfort. The problems facing the use of BIM in designing sustainable buildings are (1) The inconsistency of BIM software standards is not necessarily true, and if it appears, it may be due to a lack of knowledge of international standards, (2) the lack of interaction between different applications, and (3) the expensive price of software, hardware, and maintenance as an initial cost. Access to a BIM workflow for internal environmental quality analysis that can be used in sustainable design.

This research is a step in the way of identifying BIM as a powerful tool and a framework to achieve sustainability, which opens the way for more research on this topic. The next step by the researcher will be a case study on an already existing building. And how to convert it from a traditional building to a sustainable building using BIM and building energy simulation modelling (BEM).

\section{ACKNOWLEDGEMENTS}

Thanks and appreciation to everyone who helped collect information for this research and the researchers who reviewed their literature searches. As well as all those who participated in the questionnaire from co-workers and companies related to the design, construction and implementation processes. Special thanks to the body responsible for publishing the research, Wessex Institute at this international conference on BIM technology, which constitutes a sustainable future.

\section{REFERENCES}

[1] Berardi, U., Clarifying the new interpretations of the concept of sustainable building. Sustainable Cities and Society, 8, pp. 72-78, 2013.

[2] Khaddaj, M. \& Srour, I., Using BIM to retrofit existing buildings. Procedia Engineering, 145, pp. 1526-1533, 2016.

[3] NBIMS-US, National BIM Standard-United States ${ }^{\circledR}$, National Institute of Building Sciences, Washington, DC. http://mddb.apec.org/Documents/2013/SCSC/WKSP5/ 13_scsc_wsp5_007.pdf. Accessed on: 15 Jan. 2021.

[4] Re-izgevičius, M., Ustinovičius, L., Cibulskienè, D., Kutut, V. \& Nazarko, L., Promoting sustainability through investment in building information modelling (BIM) technologies: A design company perspective. Sustainability, 10(3), pp. 600, 2018.

[5] Li, L. \& Wang, L.X., Application of BIM technology in green building engineering construction, pp. 1301-1305, 2013.

[6] Haruna, A., Shafiq, N. \& Montasir, O., Building information modelling application for developing sustainable building (multi-criteria decision-making approach). Ain Shams Engineering Journal, 12(1), pp. 293-302, 2020.

[7] Smith, P., BIM implementation-global strategies. Procedia Engineering, 85, pp. 482-492, 2014.

[8] Krygiel, E., \& Nies, B., Green BIM: Successful Sustainable Design with Building Information Modelling, Wiley: Indianapolis, pp. 26-35, 2008.

[9] Huang, B. et al., Contribution and obstacle analysis of applying BIM in promoting green buildings. Journal of Cleaner Production, 278, 123946, 2021.

[10] Shehzad, H.M., Ibrahim, R.B., Yusof, A.F., Khaidzir, K.A., Iqbal, M. \& Razzaq, S., The role of interoperability dimensions in building information modelling. Computers in Industry, 129, 2021. 
[11] Kamel, E. \& Memari, A.M., Review of BIM's application in energy simulation: Tools, issues, and solutions. Automation in Construction, 97, pp 164-180, 2019.

[12] Shin, M., Lee, H. \& Kim, H., Benefit-cost analysis of building information modelling (BIM) in a railway site. Sustainability, 10(11), p. 4303, 2018.

[13] Lim, Y., Building information modelling for indoor environmental performance analysis. American Journal of Environmental Sciences, 11(2), pp. 55-61, 2015. 